and that the mind is depressed in a very similar manner as the barometer shows in a lesser or coarser degree the atmospheric changes. I must not presume to occupy more of your space, and I would only point out that the logical conclusions following on the above facts are, in my opinion, of almost vital importance both from a medical and meteorological point of view; in fact, the field is tremendous in which important work may be developed based upon these facts.

I would suggest that the medical men who have discovered these facts as stated in your article entirely back up my theory, but which I explain in quite a different manner. And it is interesting that I arrived at somewhat similar conclusions by an entirely different route. I concluded these suicidal tendencies would coincide with weather conditions from my own observations and therefore I look upon the work of these medical men as corroborative. The reason that the suicidal tendency is so obvions during the very finest weather conditions is as follows. It is during the finer weather conditions that the part of the mind which is affected by these conditions would naturally be in that lighter or elevated condition. But a coming atmospheric depression would naturally have a more serious depressing effect upon a mind in that elevated condition ( $I$ can express it in no other way) and therefore the mental depression would be most severe by the greater contrast. Surely bright and beautiful weather would not of itself be a cause, as suggested, for allowing man to feel these tendencies in a greater degree, but would rather act in the reverse direction, except in very abnormal cases. Surely it would be more reasonable to expect that it would be during the depressed weather conditions that those unhappy tendencies would be produced. But that I think it will be found not to be the case. Had it been so it would nndoubtedly have been known in very early times, and I think if the interesting statistics worked out by these medical men are compared along with my theory it will be found that the periods of suicidal tendency will coincide with about three or four days in advance of atmospheric depressions coming on during finer weather conditions of the atmosphere. One possible outcome of this theory will be found in that considerable information may be gleaned by mental specialists, and I would be only too pleased to give all possible assistance $I$ can in furthering the outcome of the suggestions made public in this letter.

There is a lot of interesting corroborative matter relative to this, but being a very broad subject indeed I regret that I am not able to do it justice in even this rather lengthy communication.

I am, Sir, yours faithfully,

Datchet, Bucks., Sept. 4th, 1908.

F. H. SMITH.

\section{THE RÔLE OF THE LYMPHATIC SYSTEM IN THE MECHANISM OF BODILY DEFENCE.}

\section{To the Editor of THE LANCET.}

SIR, - The Cavendish Lecture on the Etiology of Pulmonary Tuberculosis delivered by Sir William Whitla and published in your columns on July 18th was of very great interest, dealing as it does with a recent phase of the problem of tuberculosis. In his very able and lucid address the author supports the thesis of our eminent French confrèrcs, MM. Calmette and Guérin of Lille, that in the immense majority of cases pulmonary tuberculosis is not contracted by inhalation but secondarily to intestinal infection by metastasis to the lungs. The results of their experimental demonstrations on young and adult guinea-pigs performed some two years ago being confirmed, the account is very remarkably convincing while one reads, yet certain important factors have been overlooked in the apparently faultless technique of these experiments, and the significance of some of the results obtained has not been duly appreciated.

It is assumed by the Cavendish lecturer that the function of the Iymphatic glands is merely one of filtration, and this very prevalent idea is one that must at the outset be disputed. But first let attention be drawn to a most interesting series of observations contributed by Mr. C. J. Bond in the Address in Surgery delivered at the seventy-third annual meeting of the British Medical Association at Leicester in 1905. The address is on Ascending Currents in Mucous Canals and Gland Ducts and their Influence on Infection- a Study in Surgical Pathology. The distinguished surgeon and observer sums up his conclusions in the following words: "I think from the observations I have described we may consider it proved that by some means or other, and under certain conditions, particles of an insoluble substance sueh as indigo, inserted into the orifices of a mucous canal or duct, are conveyed along the mucous channel on a reverse directian to that taken by the contents of the tube, or by the secretion or excretion of the glands along such ducts." (The italics are mine.) And again, "the bearing of these remarks on the larger question of infection will at once be apparent."

Now it will be agreed that there is little or no difference between the finely divided insoluble particles of indigo, and those of finely divided carbon particles, such as of china ink, as employed respectively in the experiments of Mr. Bond and $M$. Calmette. It is true that proportionately to the size of the animals a much smaller quantity of the indigo was used by Mr. Bond than the quantity of carbon employed by M. Calmette and Sir W. Whitla in the guinea-pigs and rabbits. Although these small rodents do not ruminate, there are strong reasons for suspecting a regurgitant flow to take place from their stomachs along the csophagus and into the naso-pharynx when an emulsion of oil and carbon is injected into the presumably empty and contracted stomach. Such an occurrence would, of course, completely vitiate the results of the experiments. The only experiments in which the œsophagus was ligated were the inhalation experiments with soot, when it is presumed that neither the phrenic nor the pneumogastric nerves were included in the ligature or otherwise disturbed.

In these cases, as was to be expected, the nasal breathing and the adequacy of naso-pharyngeal sifting effectually excluded the soot carbon particles from the lung alveoli in any appreciable amount. But there is a considerable difference between the physical properties of the ultimate particles of soot and those of the crystalline particles of china ink and coal dust. And the differences of density of these inert particles are important and worthy of consideration. The soot particles inhaled would not come into immediate contact with the epithelium, but would be separated from it by the all-pervading mucus. They would therefore not originate the same stimuli, as would the more solid particles which were not in suspension but in actual contact with the epithelium. Moreover, the particles that passed through the mucus and became imbedded in the epithelial cells might be removed by desquamation of these cells. Those only wonld penetrate deeper which were spicular or crystalline, and the more so, when they came under the pressure effects of the opposing contractile tissues of the viscus. The lubricating effect of the oil on these particles would further assist the penetration by puncture as might arise in this way. And after the occurrence of such extensive puncturing the other less spicular particles might be enabled to penetrate deeper than they otherwise would by the force of aspiration caused by the rapid flow of the blood in the underlying capillaries. ${ }^{1}$

When foreign bodies such as these carbon particles penetrate the basement membrane, the first vascular structures they must encounter are the submucous plexus of lymphatic capillaries which are more delicate than the blood capillaries underlying them, though these latter would also be penetrated soon after. And the mechanical "invasion" of these by the carbon particles could not take place without effects that are much more than mechanical Violent reflex contraction of the gut could not fail to be set up by the direct irritation of the nerve endings, which are so numerous here, and the immediate result of this would be a much greater and more rapid "diffusion" of the particles in an upward direction during vermicular action and in a downward direction during peristalsis. Further, the introduction into the stomach of insoluble foreign matter, not pabulum, in colossal doses would alone be calculated to provoke emesis without necessarily the ejection of the material in appreciable quantity. And it is conceivable that during this commotion of the viscus as much of the carbon would flow up into the oro-pharyngeal cavity over the mucous membrane as under it. It would thus arrive at the broncho-tracheal mucous membrane in efforts

1 This aspiratory force is easily observed when water is made to flow down a dry canvas hose-pipe; the air is drawn through the walls of the canvas and enters it with a hissing sound, till it is wet through, the force persisting throughout the flow of water. 
at expectoration and there it might enter the adjacent lung parenchyma. But long before this ocourred the venous capillaries of the gut would have conveyed their carbon particles directly to the lung alveoli in another direction, not necessarily by way of the thoracic duct. They would arrive as minute emboli and would produce infarctions. These results would accrue more readily in the case of the adult guinea-pig: first, beeause of the greater muscular power of the gut; and second, because of the lowered physiological activity of its intestinal lymphatic system. The great physiological activity of the intestinal lymphatic system in infanoy compared with the latent activity of the pulmonary and uro-genital lymphatics at this period of life is well known.

M. Calmette and his colleagues assert a similarity, if not identity, between the physiological interactions which occur when carbon particles are laid on the mucous surfaces and when the venomous non-motile tubercle bacilli alight on the same surfaces of the living animal body. And I submit that this comparison is not scientifically justified and is indeed misleading. On the one hand we have the comparatively innocuous and inert carbon particles which are insoluble, therefore unabsorbable, and not capable of utility in the body; on the other hand we have living entities in different stages of chemical activity capable of adapting themselves to certain moist surfaces under certain conditions. They are then capable of rapid proliferation and destruction of the epithelium of their host. Profound organic and chemical processes with far-reaching effects on their host result from the excretion of their soluble toxins. Owing to the vitality of these "particles," though non-motile, they cannot be said to be inert, and though passive they are not so capable of being transported through the tissues by mechanical means or by the aspiratory force referred to above.

It must be realised that the experiments described in the Cavendish lecture are interferences with a delicate and elusive chain of physiological processes, beginning with Iymphatic gland stimulation, leucopoieisis, chemiotaxis, leucoeytosis, phagocytosis, the elaboration of antigens, and ending with the sensitisation of the colourless plasma. The normal processes are suspended and what is no less than "a state of intestinal shock" supervenes. For myself I am unable to apprehend or to accept the explanation made.

Ravenel's view, quoted by Sir William, that the alimentary traet is undoubtedly the most frequent portal of entry for the tubercle bacillus in infancy, is the one generally accepted. It is also well known that tubercular mesenteric glands, adways acquired in infancy, do not set up tuberculosis in later life among those that survive any more than tubercular cervical glands, acquired in the intervening period of childhood and youth, set up tuberculosis in the lungs or other parts of those that survive these morbid glandular states. On the contrary, pulmonary tuberculosis is more common among those who have showed no sign of these glandular involvements and therefore without the measure of immunity conferred by these states.

I would recall the important contributions by M. Calmette and M. Guérin on the immunisation of cattle by their tubercle-feeding experiments in these ruminants, which are practically indirect tubercle vaccination. As clinicians we must place the results of these along with those obtained by Dr. A. Latham of St. George's Hospital in mouth imomunisation and those obtained by Dr. J. P. Parkinson in retal immunisation. These are, however, matters to which I have referred at greater length in a monograph ${ }^{2}$ in which I claim to have anticipated the ophthalmo-reaction of Calmette and the cuti-reaction of von Pirquet. I am, Sir, yours faithfully

New,Cavendish-street, W., Sept. 7th, 1908. H. D. MoCuLLach.

\section{THE EATING OF RAW MEAT. To the Editor of THE LANCET.}

SiR,-Under the above heading Mr. W. H. Kesteven cited a case and asked suggestions as to treatment of diarrhoea and sickness accompanied by abnormal craving for raw meat the communication appearing in THE LANCET of May 23rd, 1908, p. 1527. I get my copies of THE LANCET late and am sometimes later still reading them, which must be my excuse for the long interval before you can get this letter.

2 Stray Leaves and Some Fruit on Cancer and Tuberculosis, based upon Physiological Chemical Principles.
It is at least probable that Mr. Kesteven's patient is suffering from chronic bacillary dysentery and which frequently affects the nervous system in a marked degree and may have caused both the vomiting and perverted appetite. I would suggest that Mr. Kesteven have the patient's stools examined for the dysentery bacillus and if this be present probably all symptoms will yield to a course of sulphate of magnesia purges, or if this fail daily boracic rectal injections, or if this fail, then subcutaneous injections of anti-dysenteric serum. I am, Sir, yours faithfully,

A. E. TAYLOR, M.A., M. D. Cantab.

Outtrim, South Gippsland, July 19th, 1908.

\section{THE GASTROSCOPE OF ROVSING.}

\section{To the Editor of THE LANCET.}

SIR,-Since my article appeared in THE LANCET of June 13th, p. 1689, I have had so many inquiries concerning the gastroscope of Rovsing and where it may be obtained that perhaps you will be good enough to allow me through your journal to say that the makers of this instrument are Messrs. Loewenstein of Berlin, and the London agents for this firm are "The Surgical and Electro-Medical Instrument Co.," from whom it may be obtained.

Sunderiand, Sept, 7th, 1908 I am, Sir, yours faithfully,

\section{MALIGNANT DISEASE OF THE STOMACH ASSOCIATED WITH MALIGNANT DISEASE IN THE CERVICAL GLANDS. \\ To the Elditor of THE LANCET.}

SIR,-Mr. Henry Morris's article in THE LANCET of August 15th on this subject will have been read with much interest. Undoubtedly the fact receives but scanty attention from the text-books. In an article full of interest in the Practitioner for April, 1905, Dr. G. Newton Pitt draws attention to this point and ascribes the first discovery of the enlargement of the cervical glands in cases of abdominal cancer to Troisier as long ago as 1886. He also gives several foreign references. According to Dr. Pitt the cervical glands are enlarged in 5 per cent. of cases of cancer of the stomach. Dr. Lauriston E. Shaw in his article on Cancer of the Stomach in Quain's Dictionary states that the enlargement of the cervical or inguinal glands has sometimes been the first symptom to attract attention in cases of gastric growth. An example of the former came under my notice about a year ago. I was asked by Mr. J. S. Stansfeld of Horndon to see a well-nourished but anæmic man who had come to him complaining of a large fixed mass above the left clavicle. It was almost certainly malignant. He had noticed the swelling for some weeks. Upon inquiry the man admitted having had a little indigestion for some months previonsly but he had not thonght it worth while mentioning it.' Examination of the abdomen revealed an epigastric tumour, probably in the stomach. The man afterwards came under the care of Dr. C. Gurney Thompson of Tottenham who tells me that before his death in January last he developed jaundice and considerable abdominal pain.

I have come across several other instances in which the cervical glands were enlarged at a late stage of the disease and have ocoasionally found it helpful in diagnosis. A case recently in the Charing Cross Hospital under Dr. W. C. Bosanquet with an indefinite epigastric swelling was found to have enlarged hard glands in both supraclavicular triangles. These suggested the diagnosis of malignant disease, which was confirmed by an exploratory laparotomy. A small nodule was removed and proved microscopically to be a sarcoma. $\quad$ I am, Sir, yours faithfully,

Chandos-street, W., August 25th, 1908. SIDNEY BOTD.

\section{AUSTRALIA FOR THE SONS OF PROFES- SIONAL MEN. \\ To the Editor of THE LANCET.}

SrR, - I have received so many letters in response to $\mathrm{my}$ article about Australia that appeared in your columns that it suggests to me the desirability of answering in the press some of the many questions which have been put. All classes of professional and military and naval men bare 